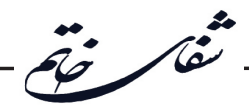

\title{
Comparison of the Effectiveness of Mental Training and Treatment Based on Acceptance and Commitment on Rumination and Worry in Subjects with Body Dysmorphic Disorder
}

Fahimeh Maheronnaghsh, Farah Naderi*, Saeed Bakhtiyarpor, Sahar Safarzadeh

Department of Psychology, Ahvaz Branch, Islamic Azad University, Ahvaz, Iran.

\section{ABSTRACT}

Introduction: Body dysmorphic disorder is one of the obsessive-compulsive disorders, which is characterized by rumination and obsessive worries about imaginary defects in appearance. Today, the significant referral of people with this disorder to dermatologists, cosmetologists, and plastic surgeons is a sign of difficulties in diagnosis and appropriate treatments for this disorder. this study aimed to compare the effectiveness of mental training : and treatment based on acceptance and commitment on rumination and worry in people with body dysmorphic disorder in Ahvaz, Iran. Materials and Methods: The research design was experimental with pre-test/post-test, control group, and follow-up. The statistical population included 280 individuals who had been referred to counseling centers in Ahvaz in 2019 due to body dysmorphic disorder. Based on the sample size of a similar research design, 100 subjects were selected voluntarily. Then 45 people who obtained the highest scores from the Body Deformity Questionnaire of Rabiee et al. (2011) were selected by purposive sampling method and randomly assigned to two experimental and one control groups. Data were collected via implementing Nolen Hocsma and Morrow (1991) Rumination Questionnaire and the Pennsylvania Concern Questionnaire (1990). Results: The results of multivariate analysis of covariance showed that in the post-test and follow-up stages, mental training and treatment based on acceptance and commitment were effective on rumination and worry. Furthermore, the efficacy of treatment based on acceptance and commitment was significantly greater than mental training. However, in the follow-up phase, no difference was observed between the effectiveness of the two interventions on rumination and worry. Conclusion: Mental training and acceptance and commitment therapy can be used to reduce rumination and worry in body dysmorphic disorder.

\section{Keywords:}

1. Body Dysmorphic Disorders

2. Acceptance and Commitment Therapy

3. Obsessive-Compulsive Disorder

\section{*Corresponding Author: Farah Naderi}

E-mail: nmafrah@yahoo.com 
مقايسةٔ اثربخشى آموزش ذهنى و درمان مبتنى بر يذيرش و تعهد بر نشخوار فكرى و نكرانى در افراد داراى بدريخت انغارى بدنى دونى

فهيمه ماهر النقش، فرح نادرى"، سعيد بختياريور، سحر صفرزاده

كروه روانشناسى، واحد اهواز، دانشكاه آزاد اسلامى، اهواز، ايران

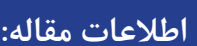

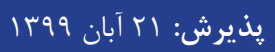

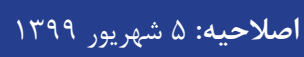

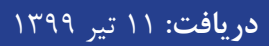

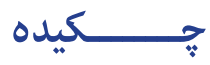

مقدمه: اختلال بدريخت انغارى بدنى جزء اختلالات شبه وسواس قرار دارد كه مشخصئ آن آن نشخوار فكرى

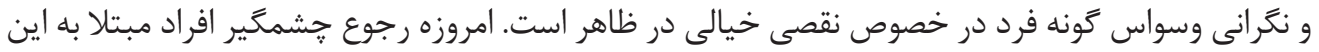

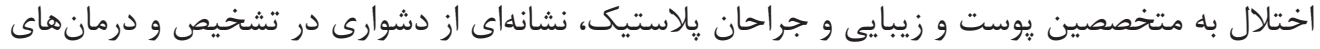

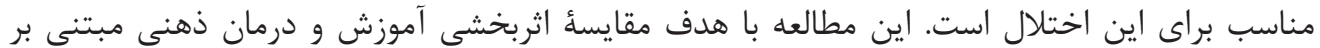

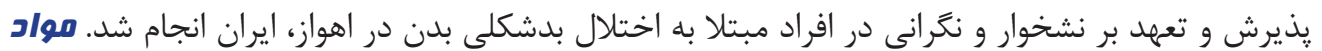

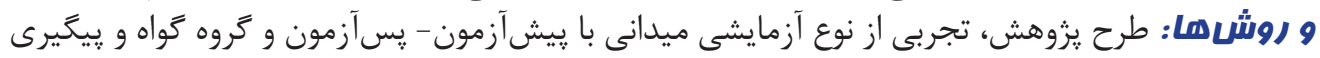

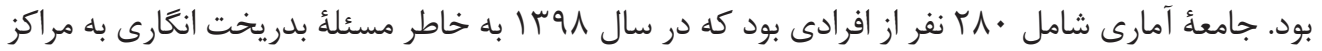

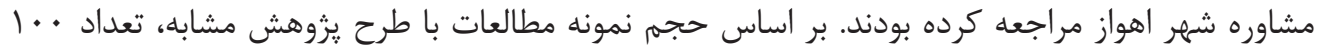

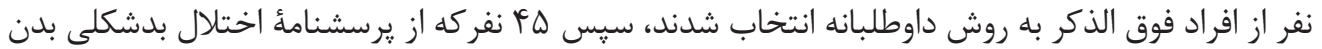

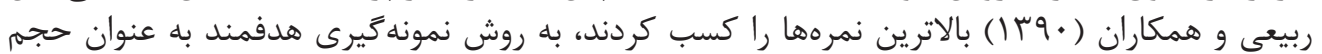

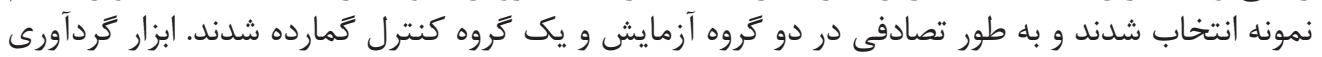

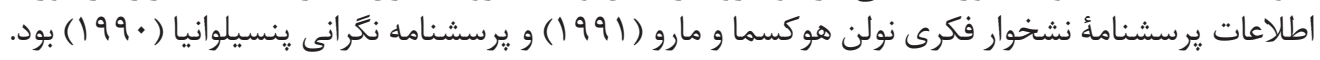

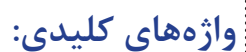

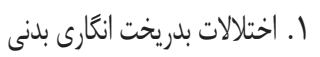

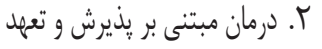

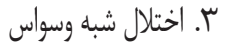

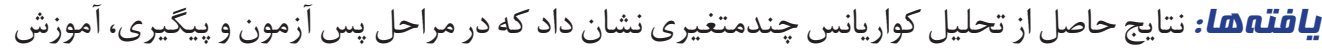

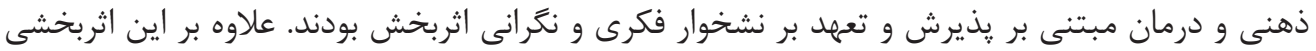

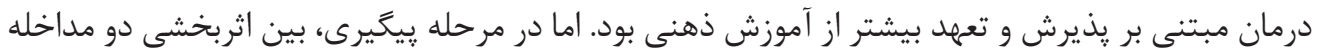

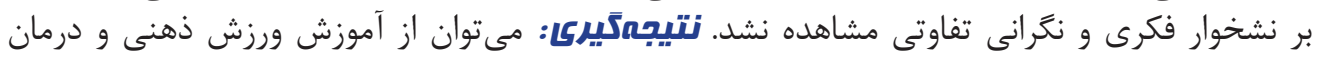

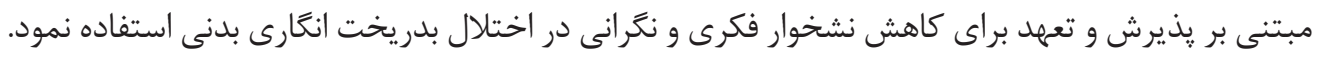




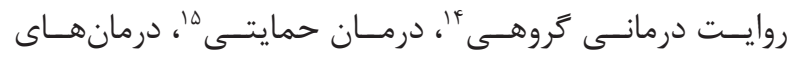

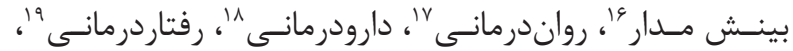

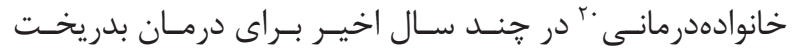

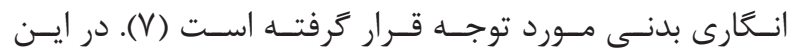

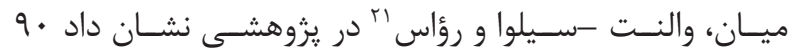

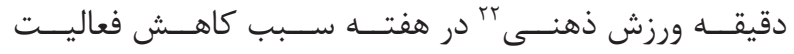

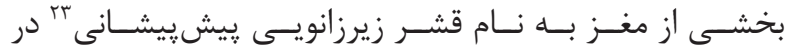

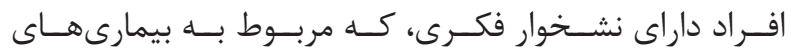

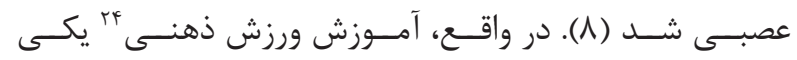

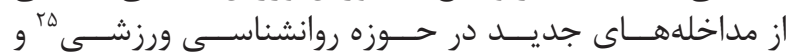

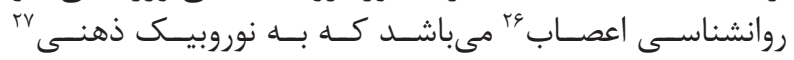

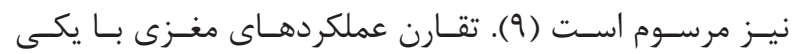

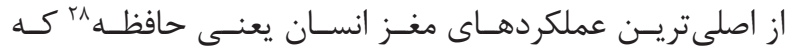

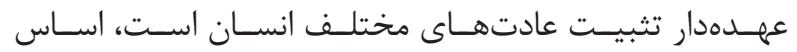

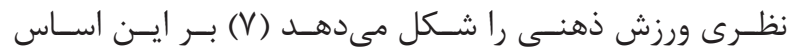

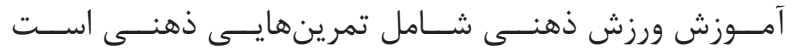

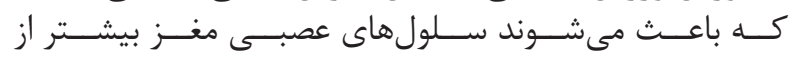

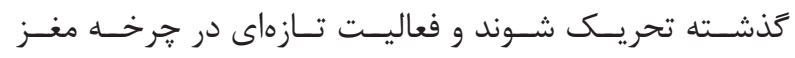

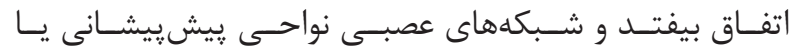

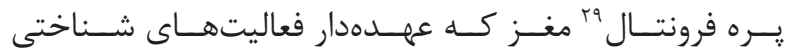

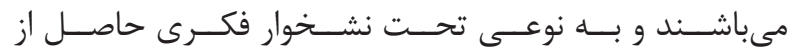

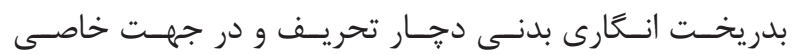

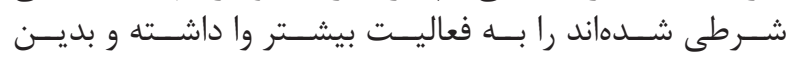

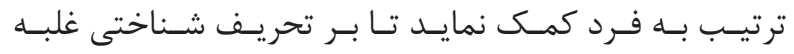

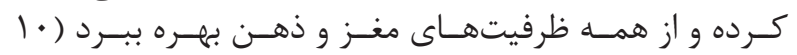

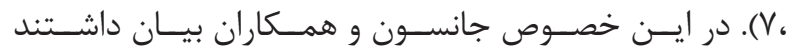

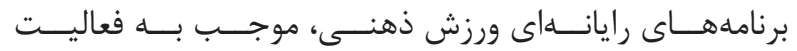

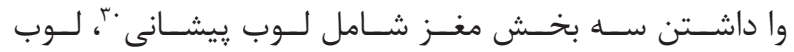

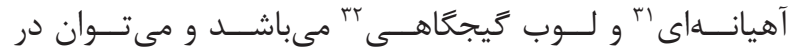

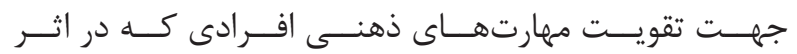

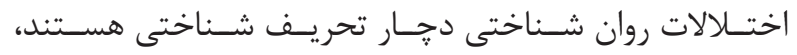

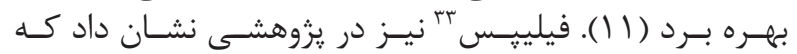

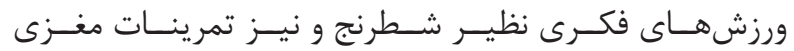

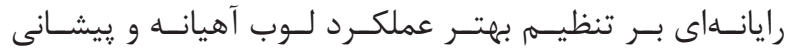

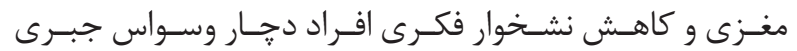

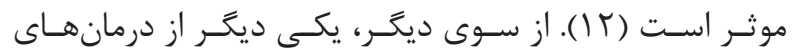

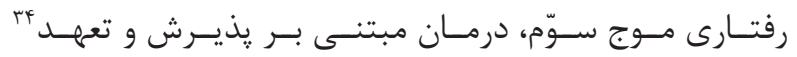

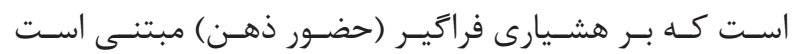

${ }^{1}$ Body dysmorphic disorder (BDD)

${ }^{2}$ DSM-5

${ }^{3}$ Pseudo obsession

${ }^{4}$ Obsessive-compulsive disorder

${ }^{5}$ Rumination

${ }^{6}$ Worry

${ }^{7}$ Eating Disorders

${ }^{8}$ Mocking disorder

${ }^{9}$ Social phobia

${ }^{10}$ Personality disorders

${ }^{11}$ Dramatic personality disorder

${ }^{12}$ Negative body image

${ }^{13}$ Cognitive-behavioral therapy (CBT)

${ }^{14}$ Narrative group therapy

${ }^{15}$ Supportive therapy

${ }^{16}$ Insight circuit

${ }^{17}$ Psychotherapy

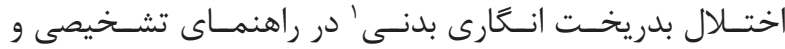

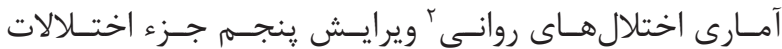

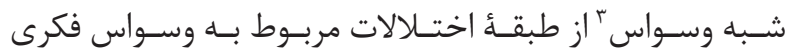

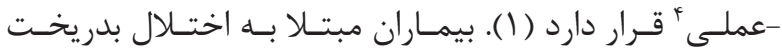

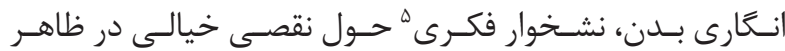

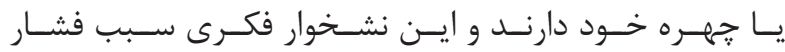

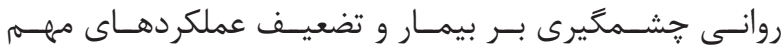

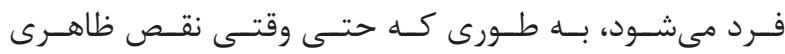

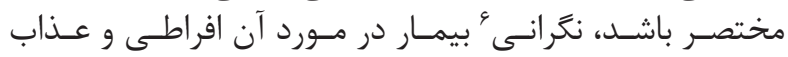

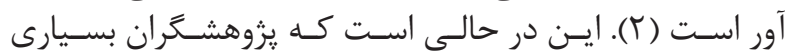

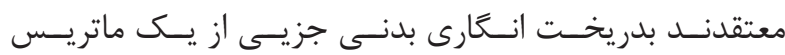

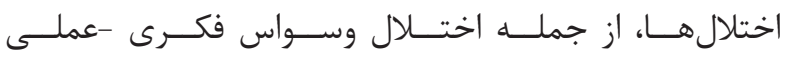

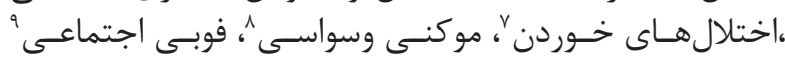

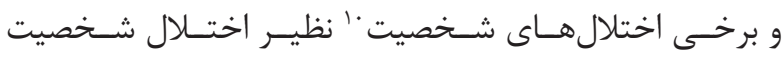

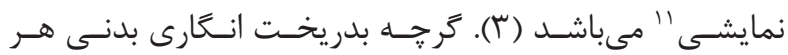

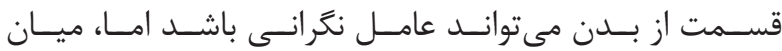

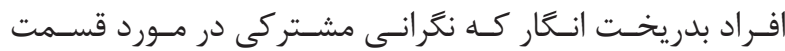

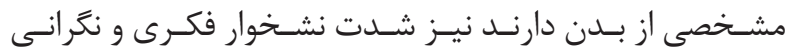

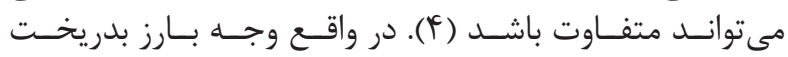

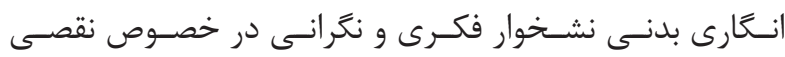

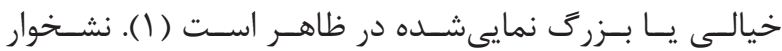

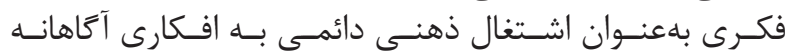

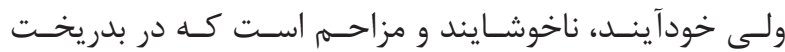

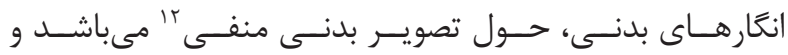

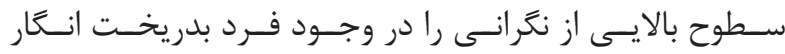

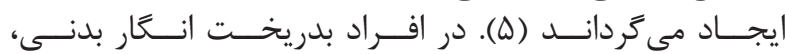

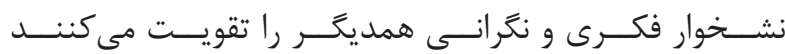

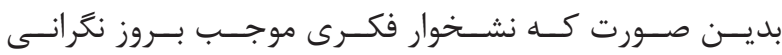

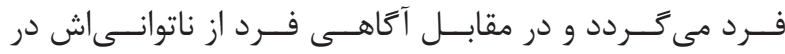

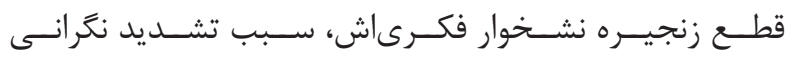

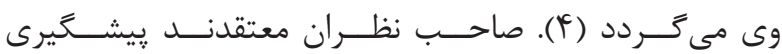

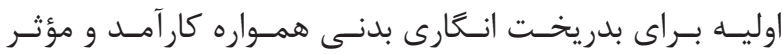

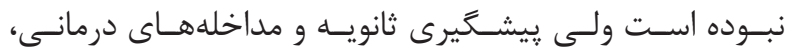

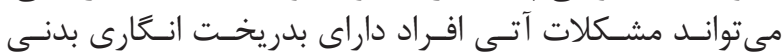

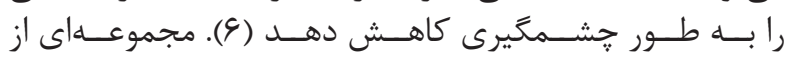

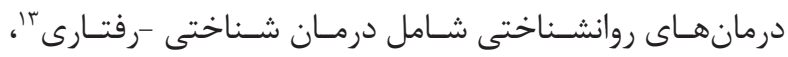

\footnotetext{
${ }^{18}$ Medicationtherapy

${ }^{19}$ Behavior therapy

${ }^{20}$ Family therapy

${ }^{21}$ Ruas \& Valente-Silva

${ }^{22}$ Mind sport

${ }^{23}$ Subgenual prefrontal

${ }^{24}$ Mental training

${ }^{25}$ Sport psychology

${ }^{26}$ Neuropsychology

${ }^{27}$ Mental neurophysiology

${ }^{28}$ Memory

${ }^{29} \mathrm{VmPFC}$

${ }^{30}$ Forehead lobe

${ }^{31}$ Parietal lobe

${ }^{32}$ Temporal lobe

${ }^{33}$ Phillips

${ }^{34}$ Acceptance and commitment therapy (ACT)
} 


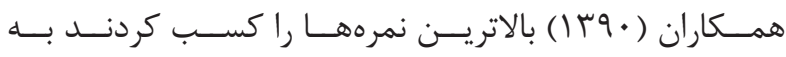

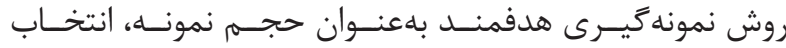

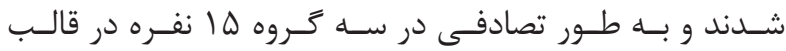

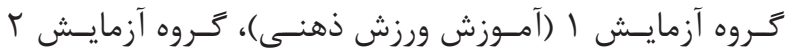

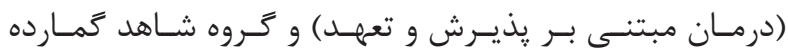

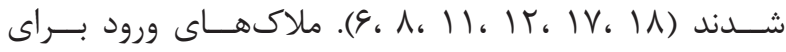

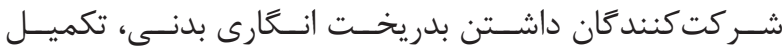

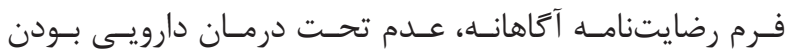

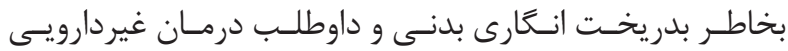

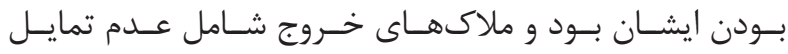

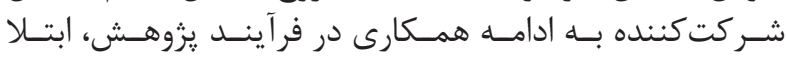

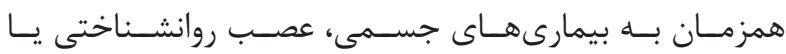

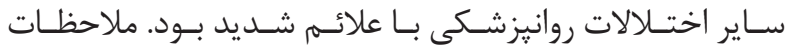

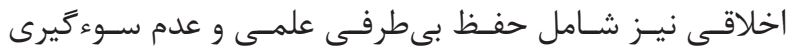

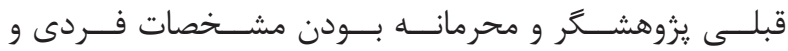

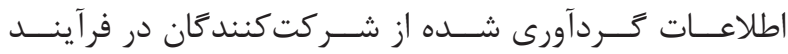

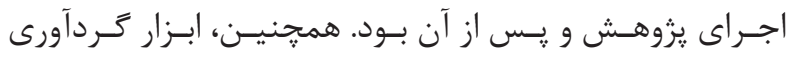

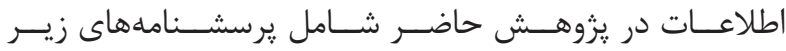

يرسشنامةٔ نشخوار فكرى نولن هوكسما و مارو (1991)

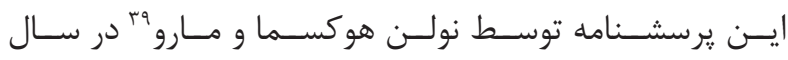

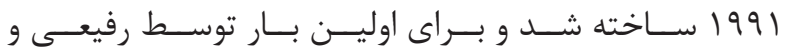

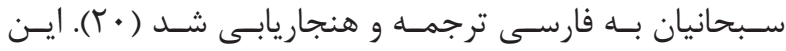

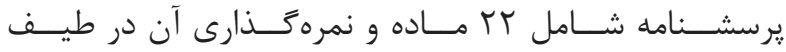

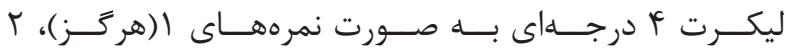

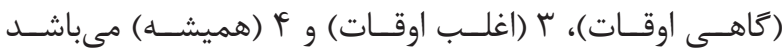

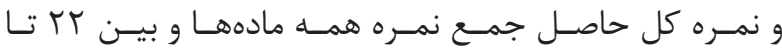

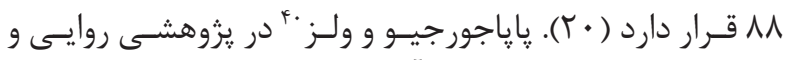

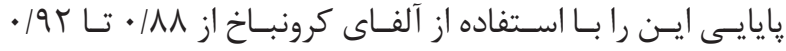

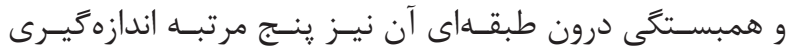

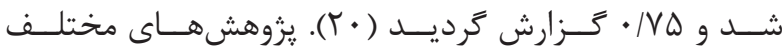

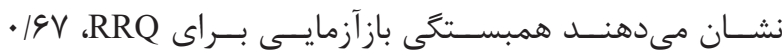

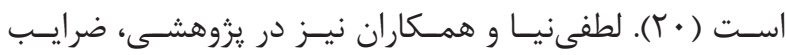

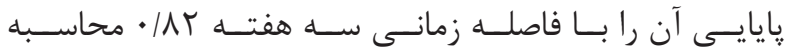

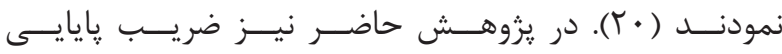

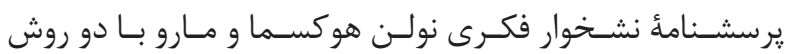

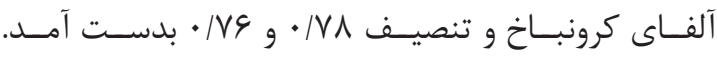

\section{برسشنامهُ نتخرانى پينسيلوانيا (•199)}

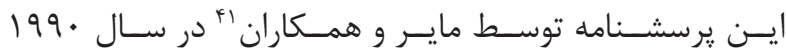

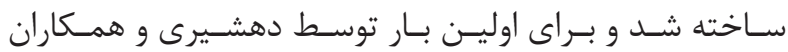

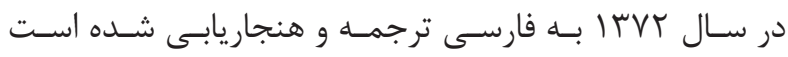

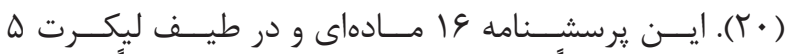

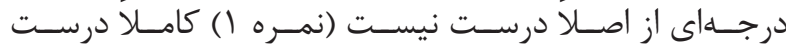

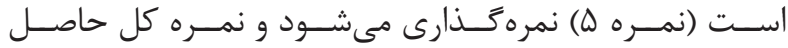

${ }^{35}$ Positive psychology

${ }^{36}$ Hodge

${ }^{37}$ Millman

${ }^{38}$ Twohig, Hayes \& Masuda

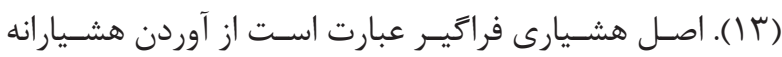

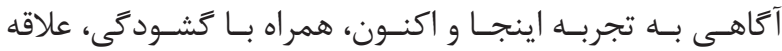

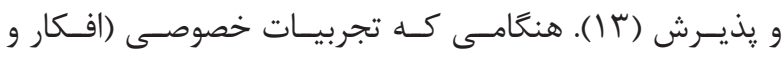

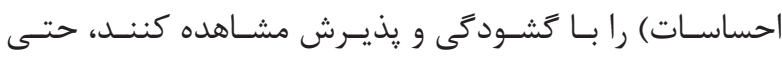

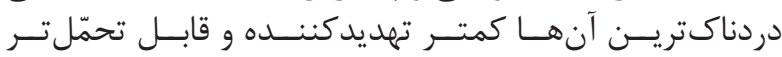

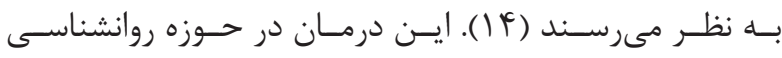

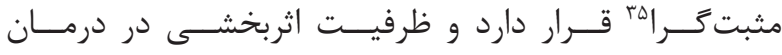

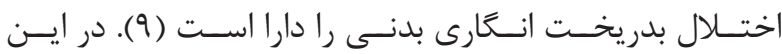

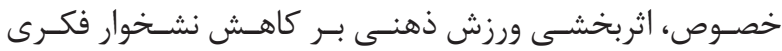

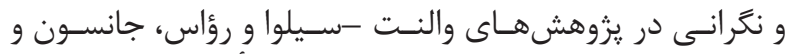

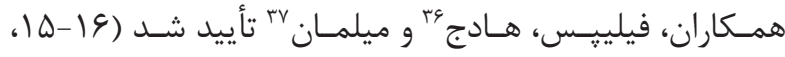

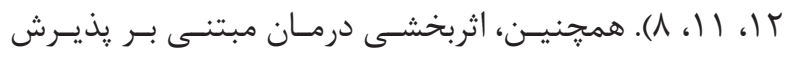

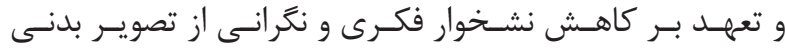

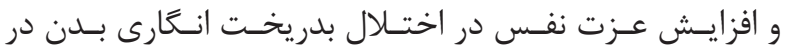

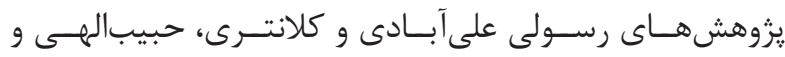

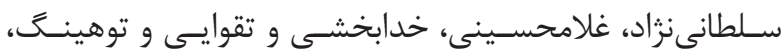

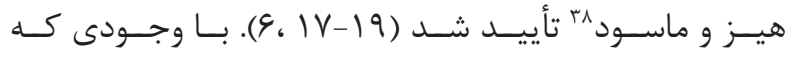

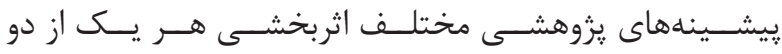

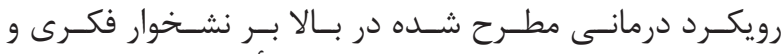

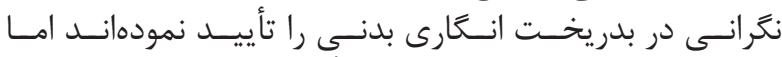

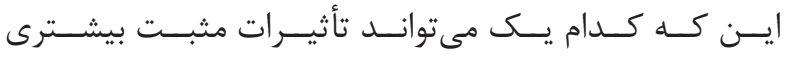

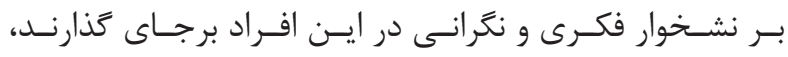

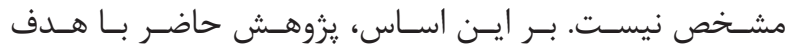

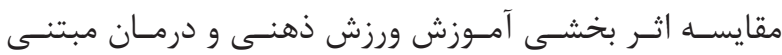

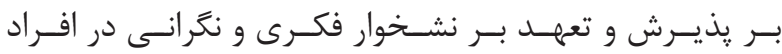

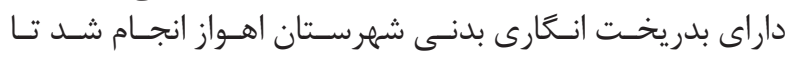

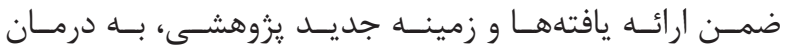

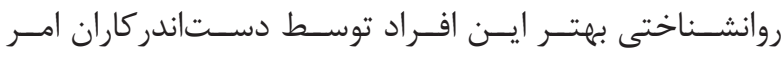
يـارى رسـاند. - ماختي

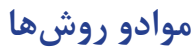

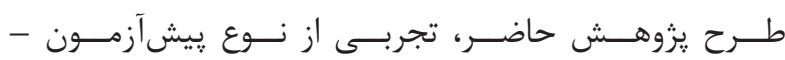

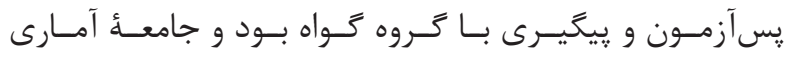

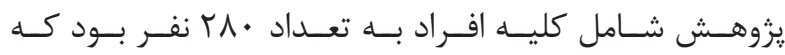

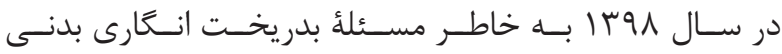

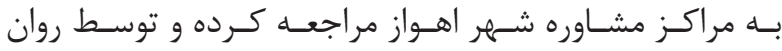

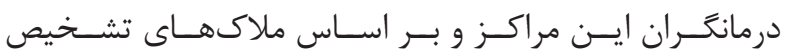

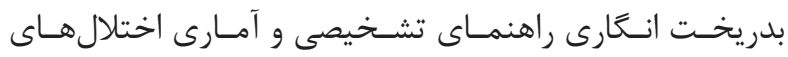

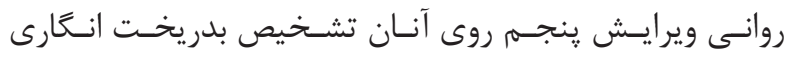

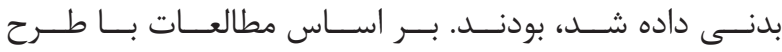

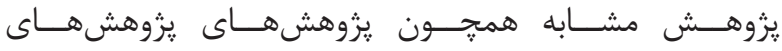

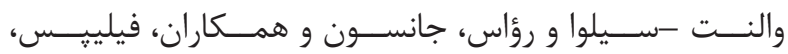

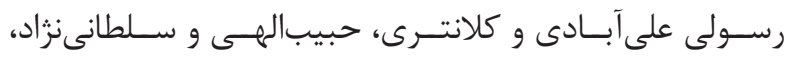

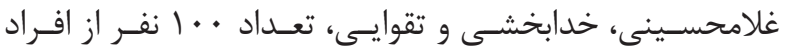

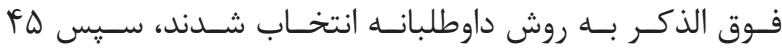

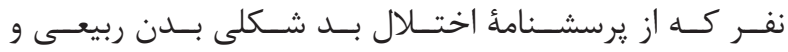

\footnotetext{
${ }^{39}$ Nolen -Hoeksema \& Morrow

${ }^{40}$ Papajorgio \& Wels

${ }^{41}$ Mayer \& et al
} 


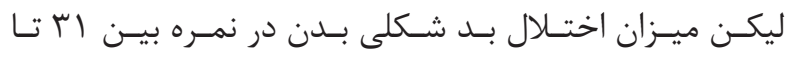

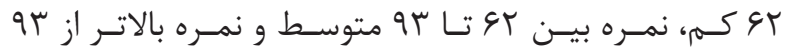

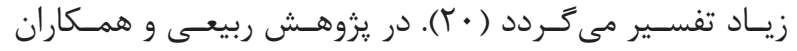

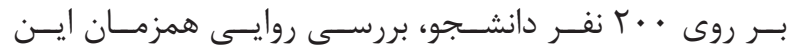

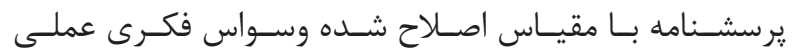

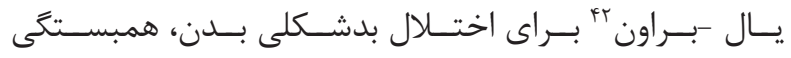

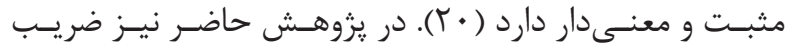

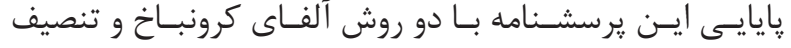

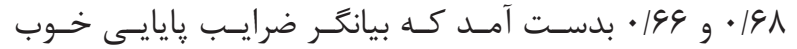

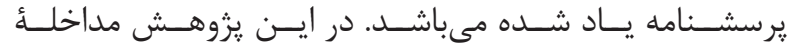

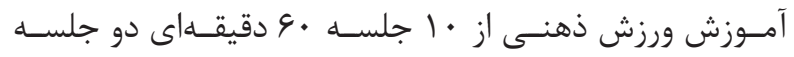

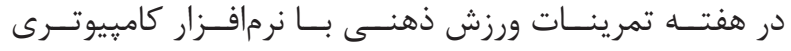

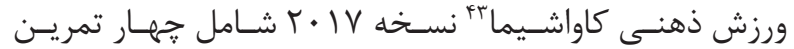

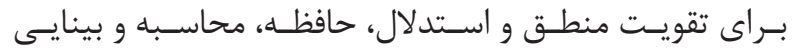

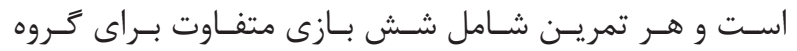

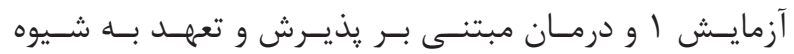

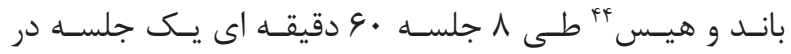

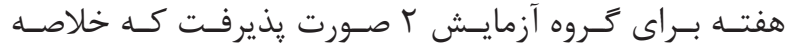

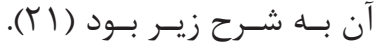

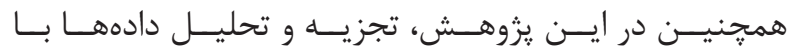

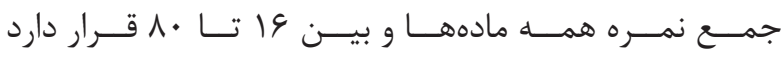

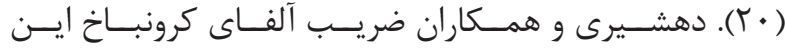

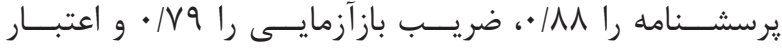

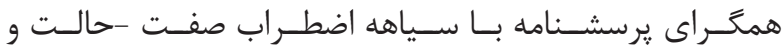

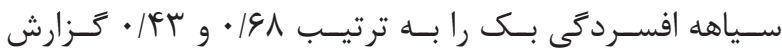

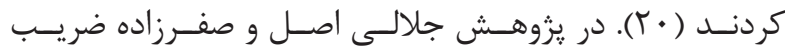

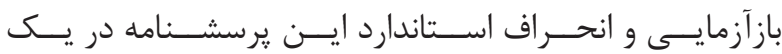

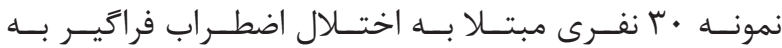

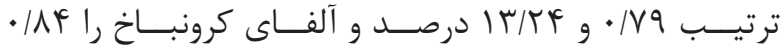

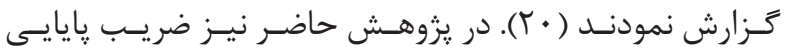

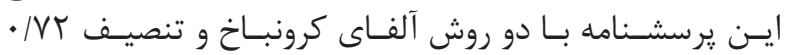

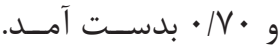

\section{يرسشنامةٔ اختلال بد شكلى بدن ربيعى و همكاران} (1rq+)

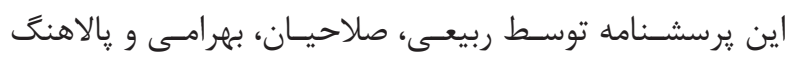

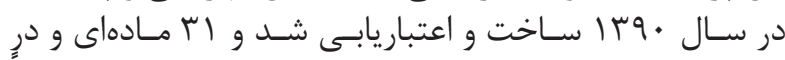

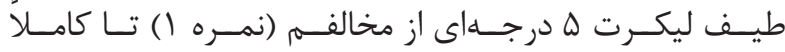

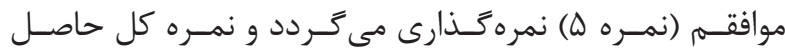

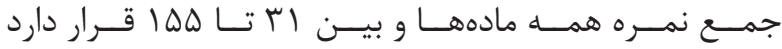

\begin{tabular}{|c|c|}
\hline شرح مختصر & جلسه \\
\hline 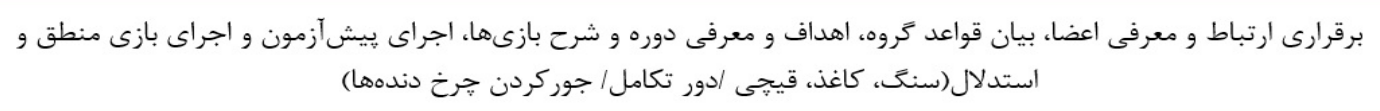 & اول \\
\hline اجراى بازى منطق و استدلال (معماى مرموز، طاس جادويى، شكلها و رنكها) & بوم \\
\hline اجراى بازى حافظه (توالى عكسها، تشخيص افراد، راه خانه من) & سوم \\
\hline اجراى بازى حاقظه (از كوتاهترين به بلندترين، اكر مىتوانى من را بكير، سبد ميوه) & جهارم \\
\hline اجراى بازى محاسبه (رياضى ساده، انجام دادن تغييرات درست، منظم كردن اعداد) & ينجمم \\
\hline اجراى بازى محاسبه (معادلات خالى، نزديكترين همسايه، محاسبه كردن) & 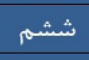 \\
\hline اجراى بازى بينايى(شناسايى جفتها، نقطههاى رنكى، نقطه نظر يا ديدكًاه) & هفتم \\
\hline اجراى بازى بينايى(مسابقه ماشين، تخم مرغها كجاست، مسالههاى كيجكننده) & 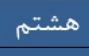 \\
\hline جمعبندى مطالب جلسات كذشته & \\
\hline اجراى دوباره بازىهاى منطق و استدلال، حافظه، محاسبه و بينايى & ets \\
\hline اجراى يسآزمون و تقدير و تشكر از شركت كنندكان & مهos \\
\hline
\end{tabular}

\begin{tabular}{|c|c|c|}
\hline تفيير رفتار مورد اتنظار & 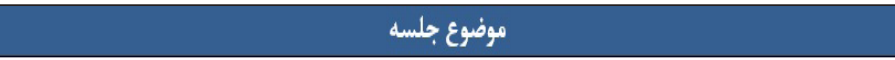 & 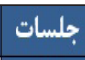 \\
\hline 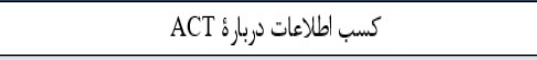 & معرفى اعضا، بيان قواعد كُوه، اهداف و معرفى دوره & ول \\
\hline عدم تلاش جهت اجتناب ز هيجانهاى منفى & أشنايى با برخى از مفاهيم درمانى ACT زل جمله تجربه اجتناب، أميختَّى و بذيرش روان & لوم \\
\hline بذّيرش رفتار و هيجانهاى منفى & اجر اي فنون درمانى ACT مانند جدلسازى شناختى، أكالهى روانى، خودتجسمى & سوم \\
\hline توجه به تجارب كنونى و لحظه به لحظه & أموزش فنون درمانى، أكامى هيجانى، أكامى خرمندانه (ستعار قربانى خود) & جهارم \\
\hline بذّيش هيجانهاو افكار منفى بدون بيشداورى و قضاوت & أموزش فنون درمانى خود بعثنوان زمينه و تمرين فنون ذهن أكالهى وأموزش تحمل بريشانى & ينجام \\
\hline تلاش در جهت أعطاف بذيرى روانشناختى الدداف براساس ازرشها & أموزش فنون درمانى ارزشهاي شخصى و روشن سازى لزرشهاو أموزش تنظيم هيجانها (لستعاره فنجان بد) & ششم \\
\hline كسب انعطاف يَيرى روانشناختى & أموزش فنون درمانى ارزشهاى شخصى و عمل متتعهلانهو و فزايش كار آمدى بين فردى (ستعاره صحنه شطرنج) & هisم \\
\hline رهايى از هيجانها و فكار منفى و كسب انعطاف بذيرى روانشناختى & مرور و تمرين فنون درمانى أموزش داده شده با تأكيد بر تنظيم هيجانها وحس معنى ارى در زندكى در لنياى واقعى & هشتم \\
\hline
\end{tabular}




\section{مافته ها}

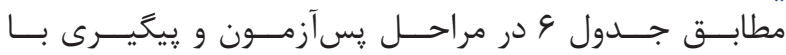

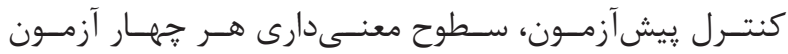

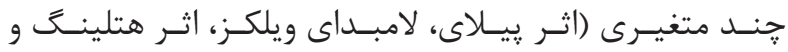

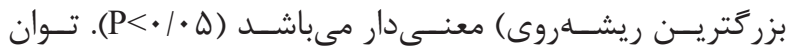

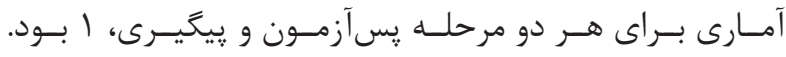

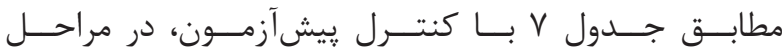

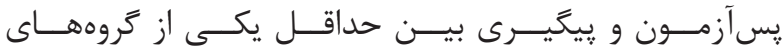

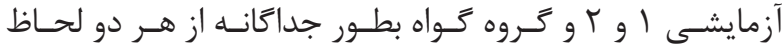

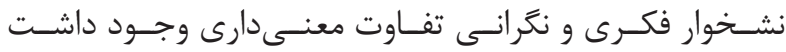

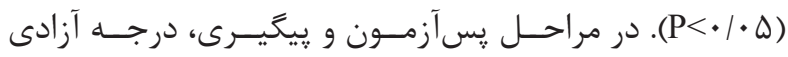

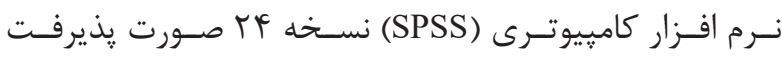

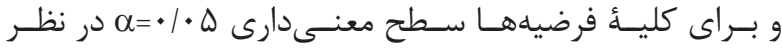

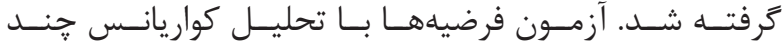

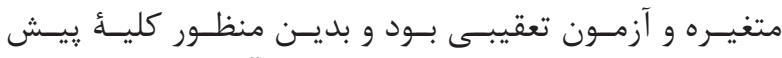

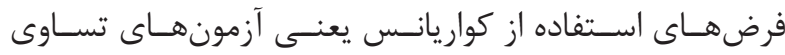

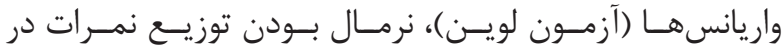

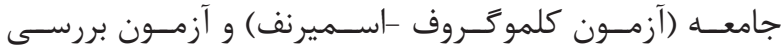

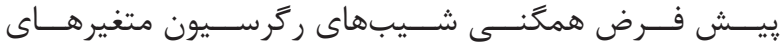

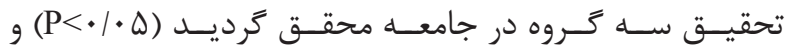

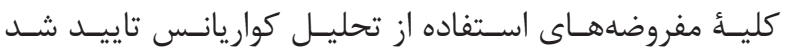

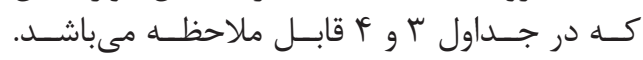

\begin{tabular}{|c|c|c|c|c|c|c|c|}
\hline \multicolumn{2}{|c|}{ هيعيرى } & \multicolumn{2}{|c|}{ يس آزمون } & \multicolumn{2}{|c|}{ هيش آزمون } & \multirow{2}{*}{ مرحله } & \multirow{2}{*}{ متغير } \\
\hline معنى دارى & آماره & معنى قارى & آماره & معنى قارى & آماره & & \\
\hline$r / \cdots$ & $\cdot / 1 \Delta \varphi$ & $r / \cdots$ & $.|| f \mid$ & $r / \cdots$ & $\cdot / 10$ & آزمايش 1 & \multirow{3}{*}{ نشخوار فكرى } \\
\hline$r / \cdots$ &.$/ 11$. & $\cdot 11 \cdot 1$ & $r / \cdots$ & $r / \cdots$ & س & آزمايش r & \\
\hline$r / \cdots$ &.$/ 118$ & $r / \cdots$ & $\cdot / 1 \cdot v$ & $r / \cdots$ & $\cdot|10|$ & كواه & \\
\hline$r / \cdots$ & .1191 & $r / \cdots$ & $.11 \cdot 9$ & $r / \cdots$ &.$/ 109$ & آزمايش 1 & \multirow{3}{*}{ تخرانى } \\
\hline$r / \cdots$ & .1 .91 & $r / \cdots$ &.$/ 1 r q$ & $r / \cdots$ &.$/ I V f$ & آزمايش r & \\
\hline$\cdot 11 \cdot f$ & $\cdot / \pi \cdot 1$ & $.1 .9 \mathrm{~V}$ & $r \cdot r$ & $r / \cdots$ & .1199 & كواه & \\
\hline
\end{tabular}

جدول F- نتايج آزمون لوين و آزمون بررسى يِيش فرض همكنى شيبهاى ركر سيون متغيرهاى تحقيق

\begin{tabular}{|c|c|c|c|c|c|}
\hline \multicolumn{3}{|c|}{ آزمون بررسى بيش فرض همحَنى شيبهاى ركرسيون } & \multicolumn{2}{|c|}{ آزمون لوين } & \multirow{2}{*}{ متغير } \\
\hline معنى & $\mathbf{F}$ & منبع تغييرات & معنى دارى & $\mathbf{F}$ & \\
\hline$\cdot / 1 \Delta V$ & l/GFr & تعامل & $\cdot / Q \cdot r$ & - 1991 & نشخوار فكرى \\
\hline .1 .90 & N/G广A & كروه * پيشآزمون & $\cdot 1 \cdot 9 \wedge$ & r/AV• & 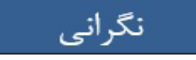 \\
\hline
\end{tabular}

\begin{tabular}{|c|c|c|c|c|c|c|c|}
\hline \multicolumn{2}{|c|}{ بيغيرى } & \multicolumn{2}{|c|}{ بس آزمون } & \multicolumn{2}{|c|}{ بيش آزمون } & \multirow{2}{*}{ مرحله } & \multirow{2}{*}{ متغير } \\
\hline انحراف معيار & ميانگين & انحراف معيار & ميانگين & انحراف معيار & ميانگين & & \\
\hline $\mathrm{V} / \Delta \Lambda$ & $r V / r r$ & D/Tr & एव/द & IT/VE & FN/G. & آزمايش 1 & \multirow{3}{*}{ نشخوار فكرى } \\
\hline$\Delta / \vee \wedge$ & ra/A. & $F / V \Delta$ & rr/A. & $1 . / 9 r$ & $\Delta 9 / F$. & آزمايش r & \\
\hline V/GF & $\Delta \Lambda / r r$ & $V / r q$ & $\Delta V / I T$ & 1/9. & $D F / G 4$ & كواه & \\
\hline $9 / 51$ & 「人/. & G/TV & rA/Vr & $\Delta / \Lambda$. & $\Delta r / \Lambda$. & آزمايش 1 & \multirow{3}{*}{ نترانى } \\
\hline $9 / 94$ & rN/AS & $8 / 99$ & rT/K. & $V / D \mid$ & $\Delta F / G$. & آزمايش r & \\
\hline$\approx 2 / 9 F$ & $\Delta V / A G$ & VIGF & $\Delta V / S$. & $F / V$. & $\Delta \Lambda / F \varphi$ & كواه & \\
\hline
\end{tabular}

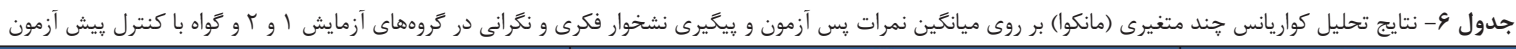

\begin{tabular}{|c|c|c|c|c|c|c|}
\hline \multicolumn{3}{|c|}{ هيخيرى } & \multicolumn{3}{|c|}{ يس آزمون } & مرحله \\
\hline سطح معنى & $\mathbf{F}$ & مقدار & سطح معنى & $\mathbf{F}$ & مقدار & آزمون \\
\hline$\cdot 1 \cdots$ & १/^f & $\cdot 19 \mathrm{~V}$ & $\cdot / \cdots$ & IT/FT & $1 / V 4$ & آزمون اثر بيلايى \\
\hline$\cdot 1 \cdots$ & Ir/fE & $\cdot /$ HF & $\cdot 1 \cdots$ & rI/K &.$/ \cdots r$ & آزمون لامبداى ويلكز \\
\hline$\cdot 1 \cdots$ & $1 V / r q$ & $1 / \wedge 1$ & $\cdot / \cdots$ & $r+/ 19$ & $|f| / r \mid$ & آزمون اثر هتلينَ \\
\hline $.1 \cdots$ & re/Tद & 1/^६ & $\cdot / \cdots$ & SVIAK & $\mid \mathrm{HN} / \cdot$ & آزمون بزرَترين ريشهروى \\
\hline
\end{tabular}




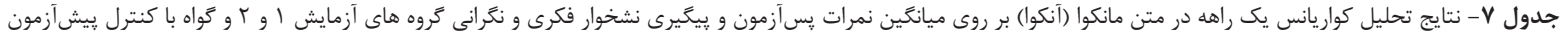

\begin{tabular}{|c|c|c|c|c|c|c|c|}
\hline \multicolumn{3}{|c|}{ بيخيرى } & \multicolumn{4}{|c|}{ هس آزمون } & \multirow{2}{*}{ مرحله } \\
\hline سطح معنى دارى & $\mathbf{F}$ & مجموع مجذورات & سطح معنى دارى & $\mathbf{F}$ & مجموع مجذورات & منبع & \\
\hline.$/ 1 F a$ & $T / T$. & $1 \cdot$ T/AF &.$/ 1 \wedge \Delta$ & $1 / 11$ & $\Delta V / F$. & يِيش آزمون & \\
\hline $.1 \ldots$ & rq/1r & refV/q9 &.$/ \cdots$ & $V Y / \cdot \Delta$ & $f \Delta \Delta \Delta / \varepsilon)$ & كروه & نشخوار فكرى \\
\hline- & - & INGF/KA & - & - & ITEF/FF & خطا & \\
\hline$\cdot 1 \ldots$ & $1 Q / \wedge \Delta$ & VQI/TY & . /THV & l/fF & $99 / F V$ & ي پيش آزمون & \\
\hline.$/ \ldots$ & rr/Vq & rTDQ/Fq &.$/ \ldots$ & $f Q / Q q$ & Frq1/rr & كروه & ن تكرانى \\
\hline$\because \quad-$ & - & $1 \wedge 9 \Delta / \Delta V$ & - & - & $19 r 8 / .1$ & خطا & \\
\hline
\end{tabular}

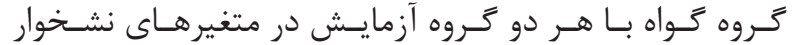

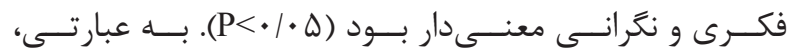

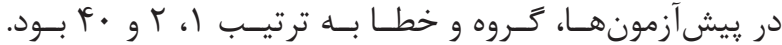

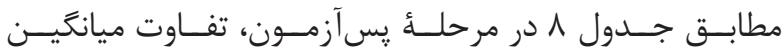

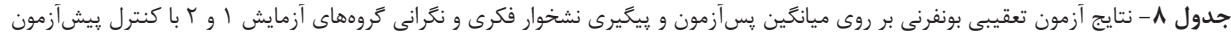

\begin{tabular}{|c|c|c|c|c|c|c|c|}
\hline \multicolumn{3}{|c|}{ يِيَيرى } & \multicolumn{3}{|c|}{ هِ آزمون } & \multicolumn{2}{|l|}{ مرحله } \\
\hline معنى دارى & خطاى استاندارد & تفاوت ميانكينها & معنى دارى & خطاى استاندارد & تفاوت ميانكينها & كروههاى مورد مقايسه & متغير \\
\hline $.1 \cdots$ & T/QV & $-19 / 19$ & .1. & T/M & $-I V / V \Lambda$ & آزمايش او تواه & 1 \\
\hline$\cdot 1 \cdots$ & $r / Q T$ & $-19 / r \Delta$ & $\cdot 1 \cdot$ & $r / .9$ & - YH/AV & آزمايش r و گواه & \\
\hline $1 / \cdots$ & $T / N$. & $\cdot 1 \cdot 1$ & $.1 . Y \Lambda$ & $T / M T$ & 91.9 & آزمايش اورr & \\
\hline$\cdot / \cdots$ & $T / N$ & $-10 / 19$ &.$/ \ldots$ & $T / N F$ & $-|N| \cdot 0$ & آزمايش او تواه & \\
\hline.$/ \cdots$ & T/G. & $-19 / \pi 9$ & $\%$ & T/GT & $-Y Y / D V$ & آزمايش r و كواه & il \\
\hline $1 / \cdots$ & T/QV & . $|\Delta T|$ & $\cdot 1 \cdot \psi \wedge$ & $r / 09$ & G/QT & آزمايش اورr & ⿶ \\
\hline
\end{tabular}

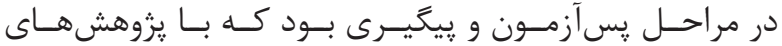

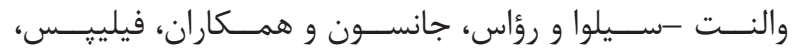

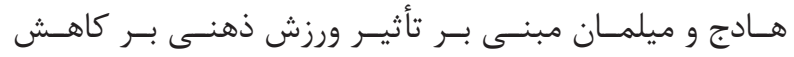

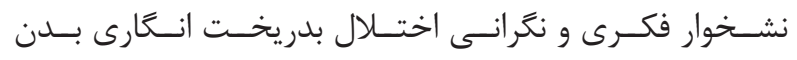

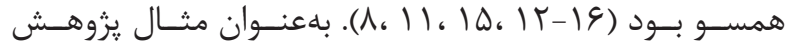

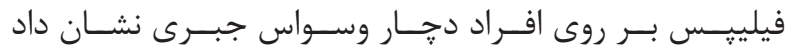

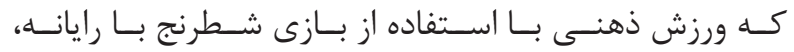

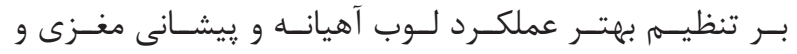

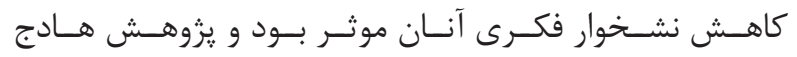

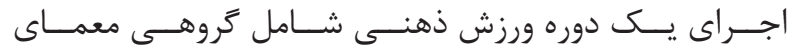

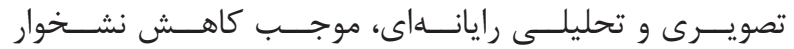

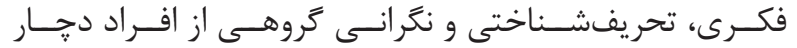

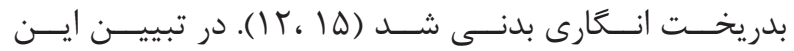

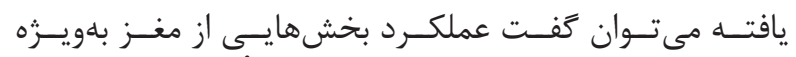

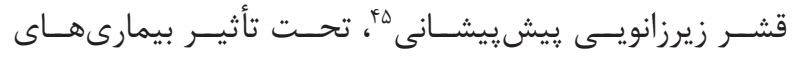

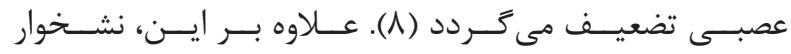

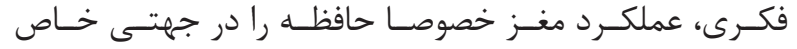

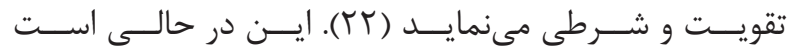

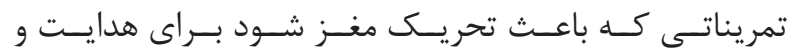

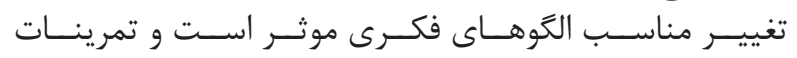

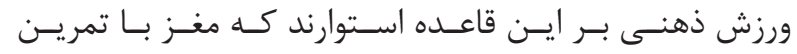

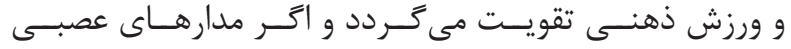

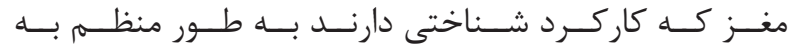

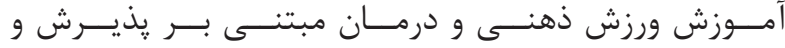

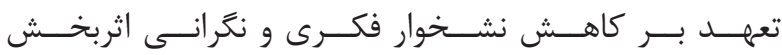

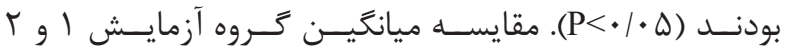

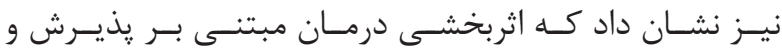

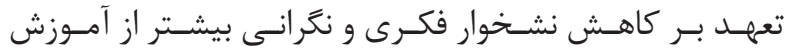

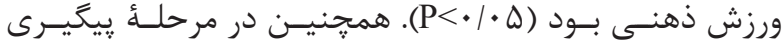

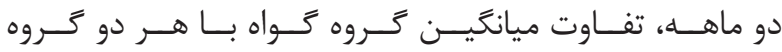

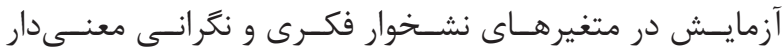

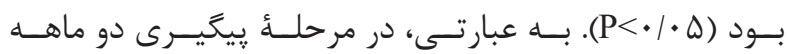

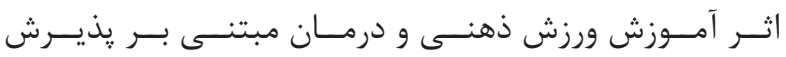

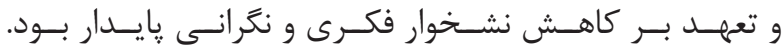

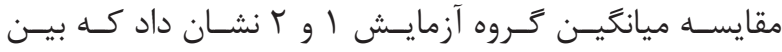

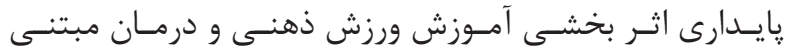

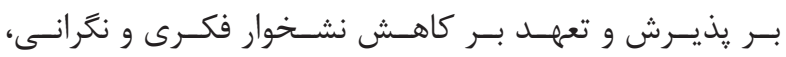

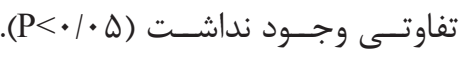

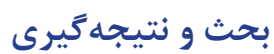

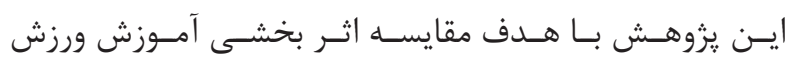

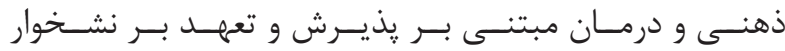

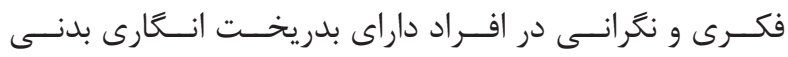

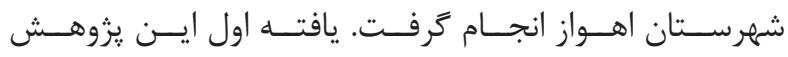

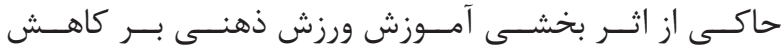

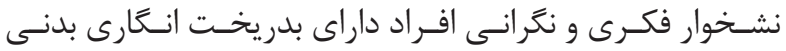

${ }^{45}$ Subgenual Prefrontal 


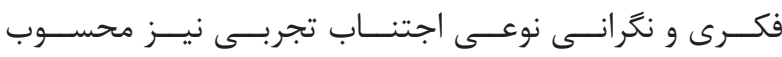

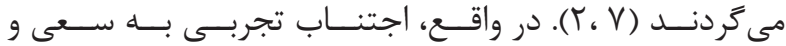

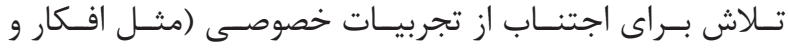

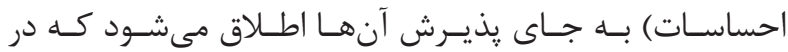

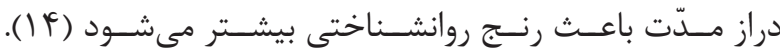

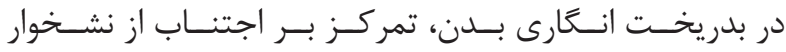

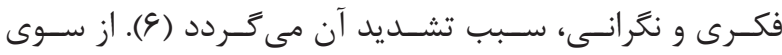

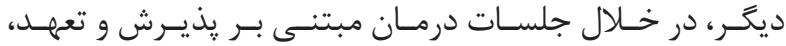

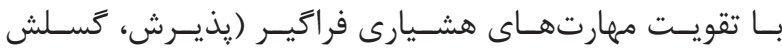

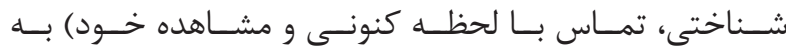

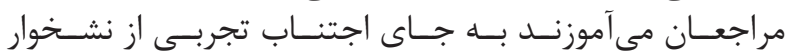

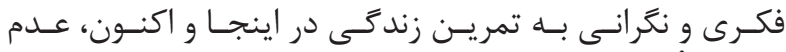

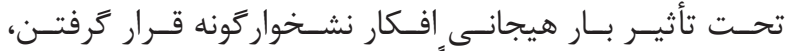

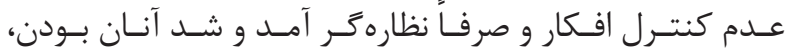

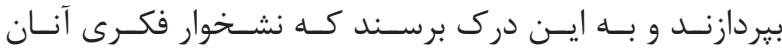

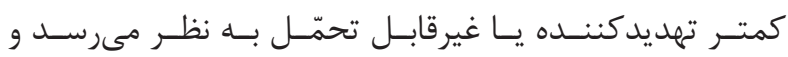

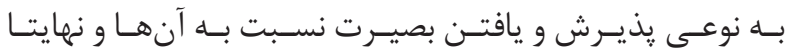

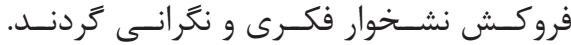

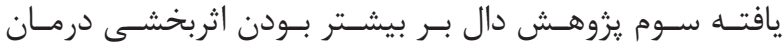

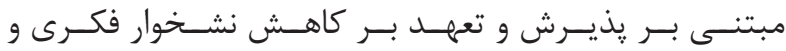

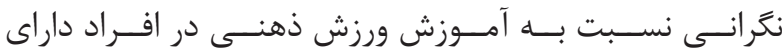

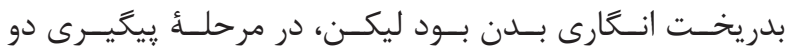

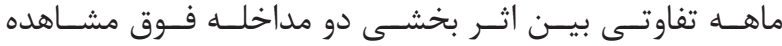

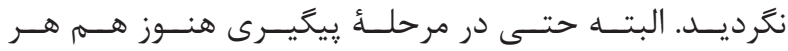

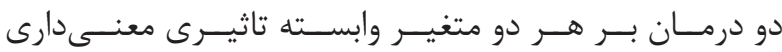

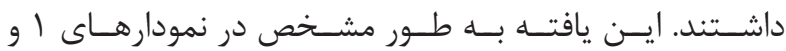

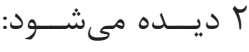

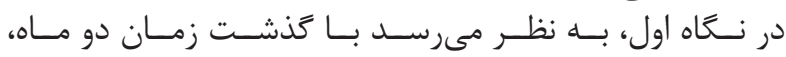

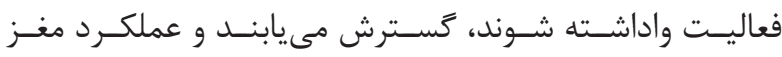

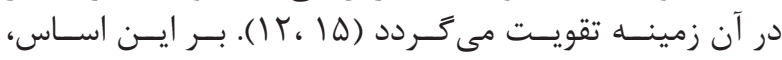

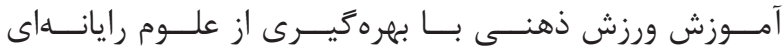

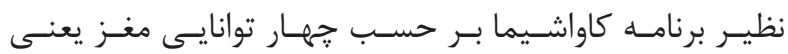

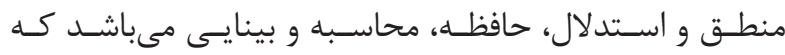

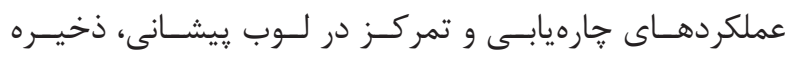

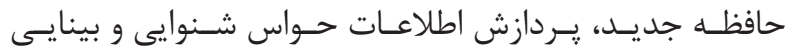

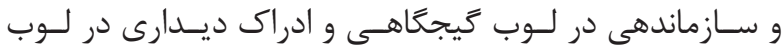

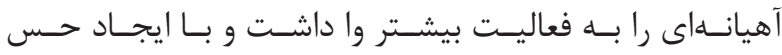

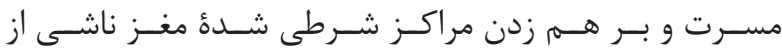

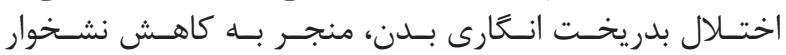
فكــرى و نكرانــى در شـــركت كنـند

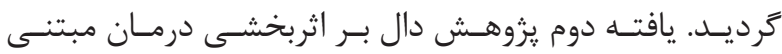

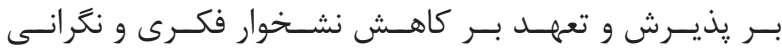

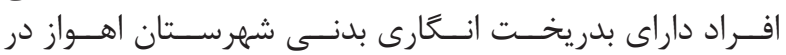

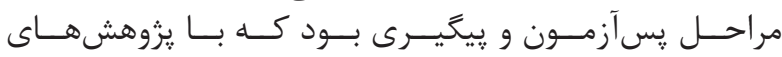

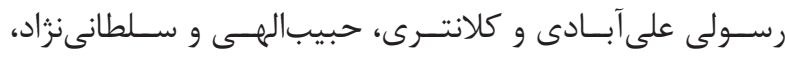

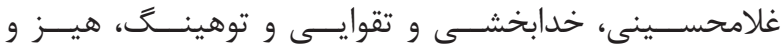

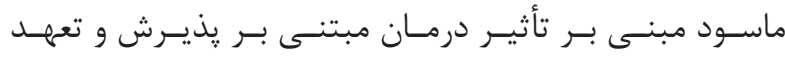

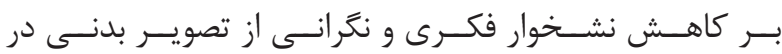

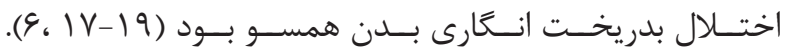

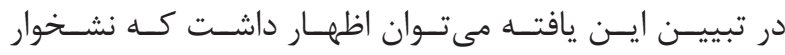

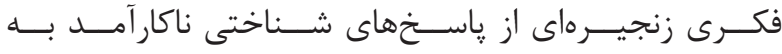

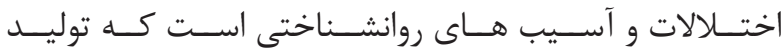

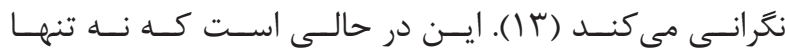

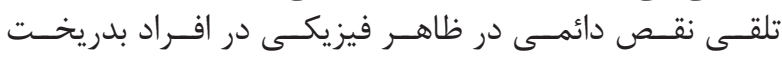

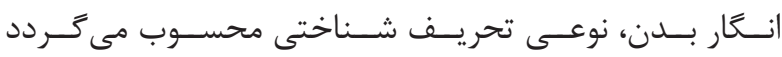

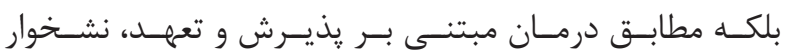

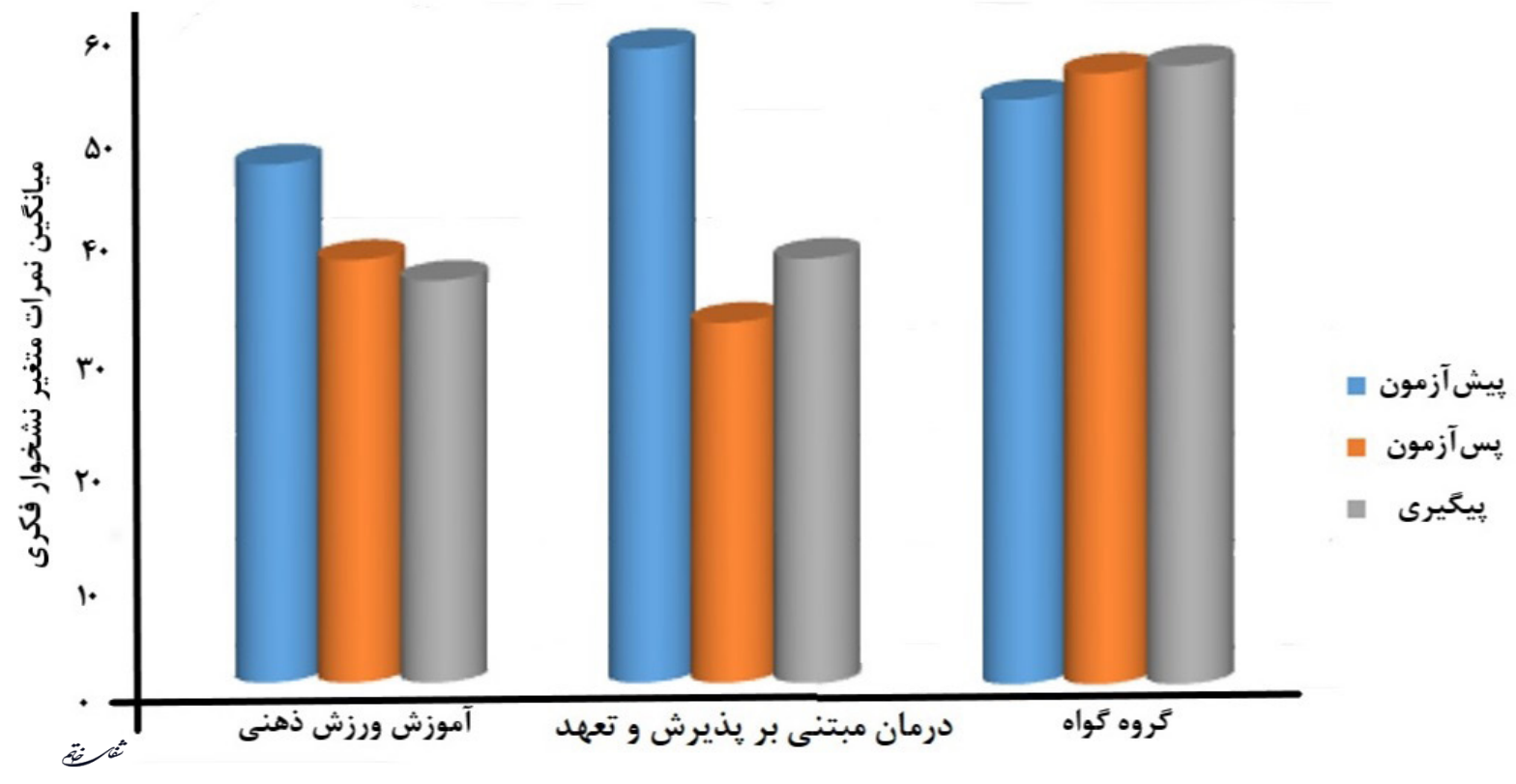




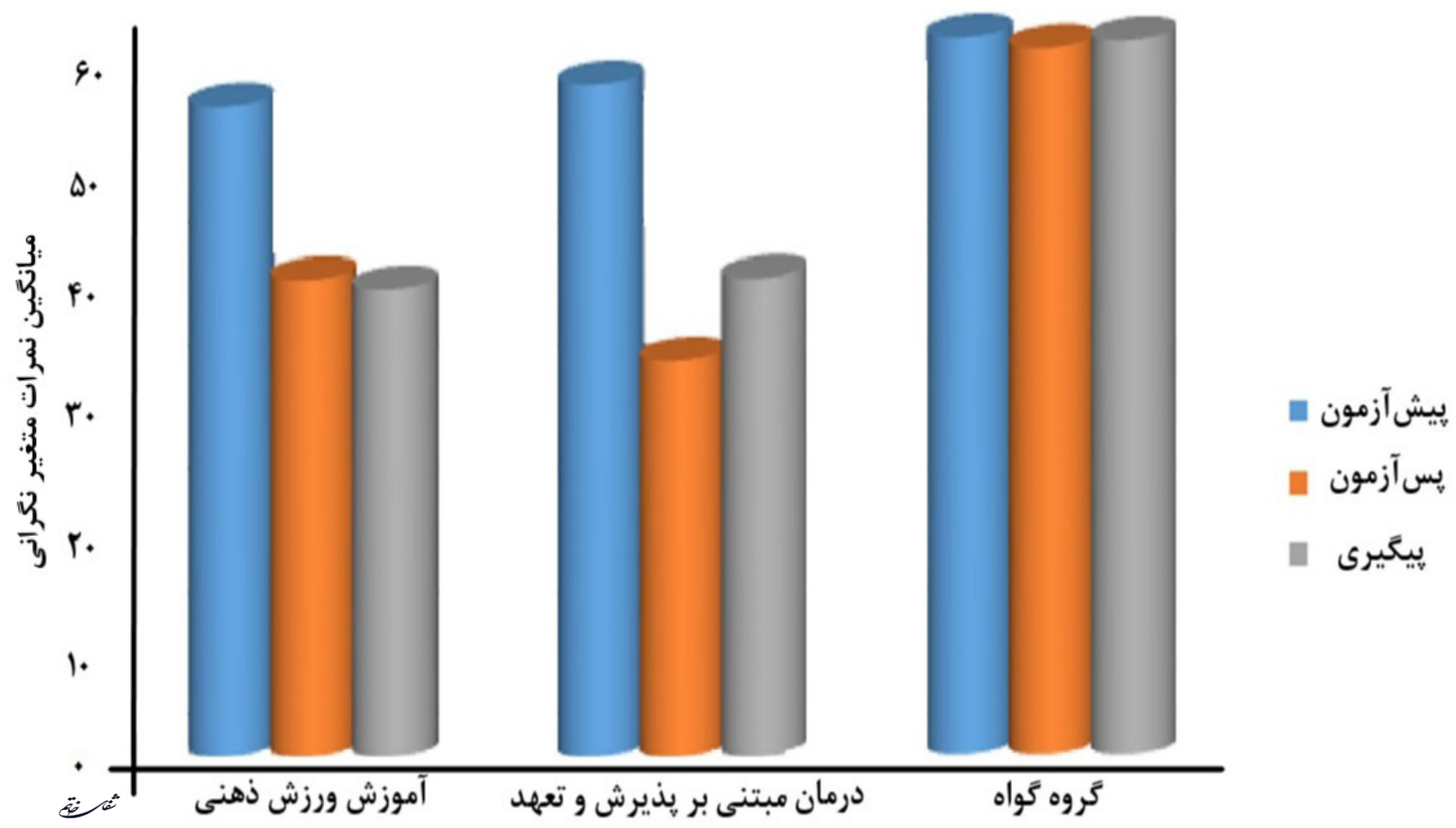

نمودار r- ميانغَين نمرات متغير نكَرانى در سه كَروه

باشــد. انتســاب تصادفـى، بــهـ تبعيـت از قوانيـن احتمـــالات

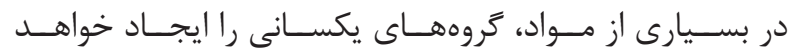

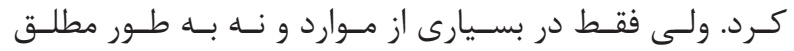

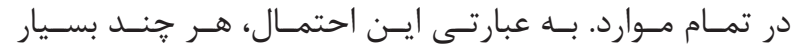

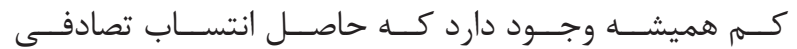

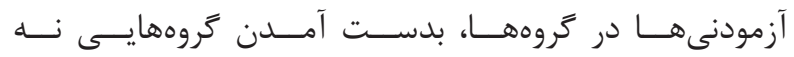

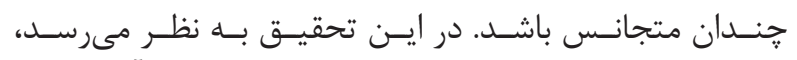

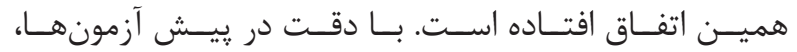

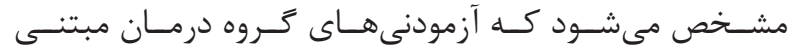

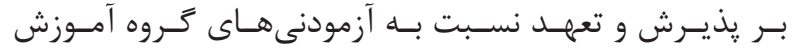

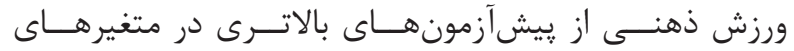

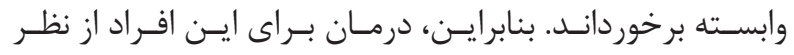

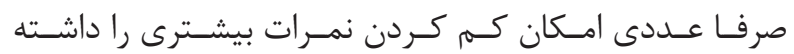

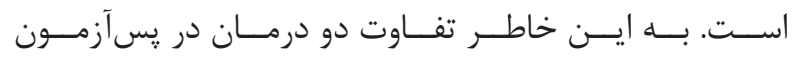

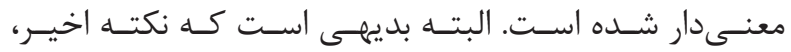

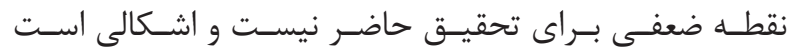

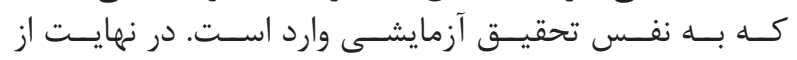

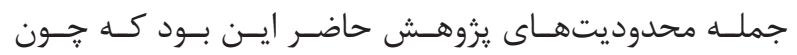

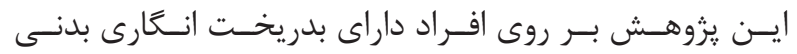

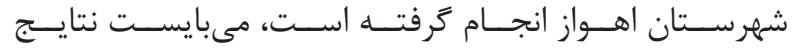

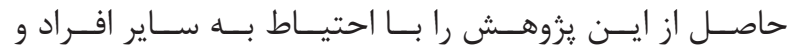

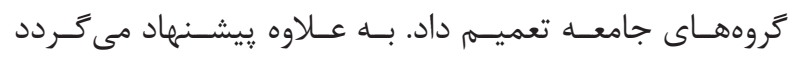

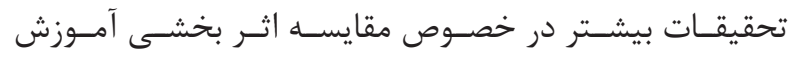

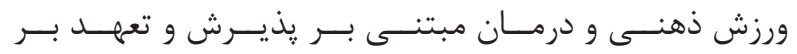

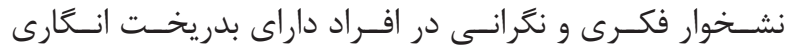

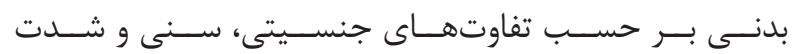

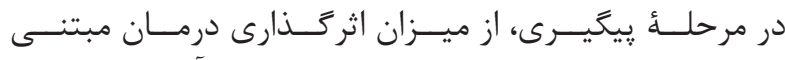

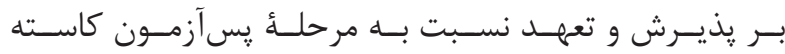

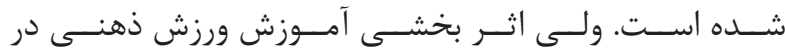

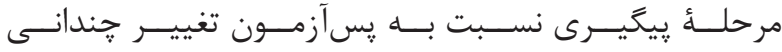

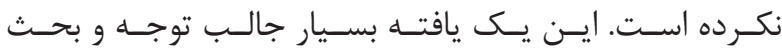

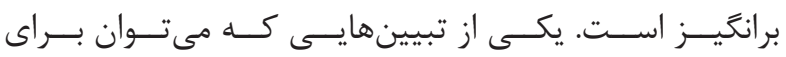

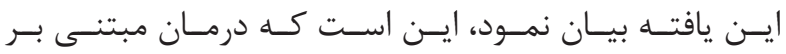

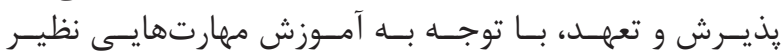

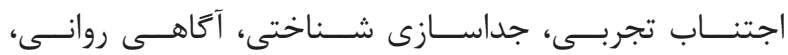

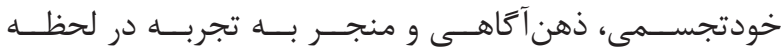

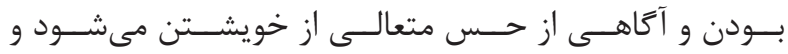

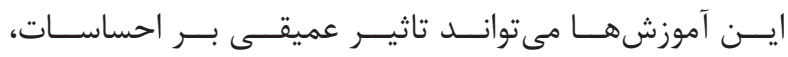

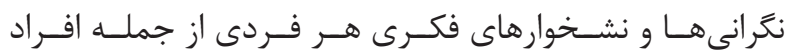

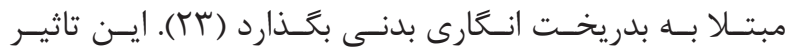

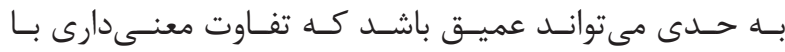

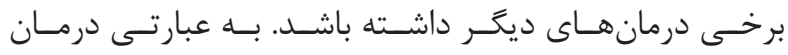

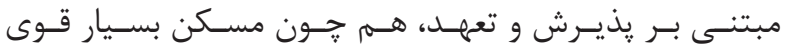

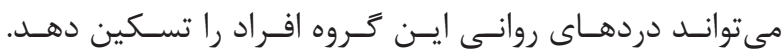

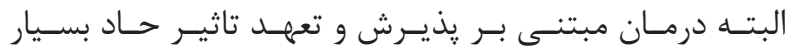

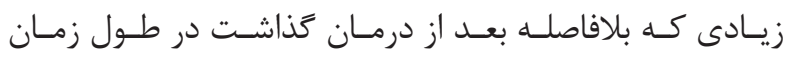

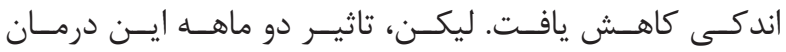

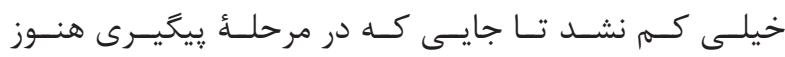

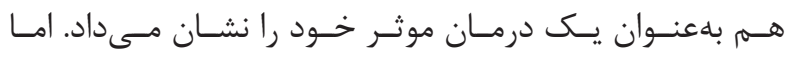

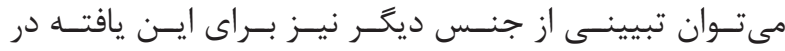

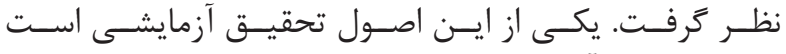

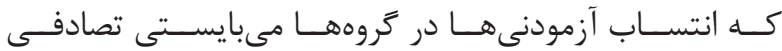




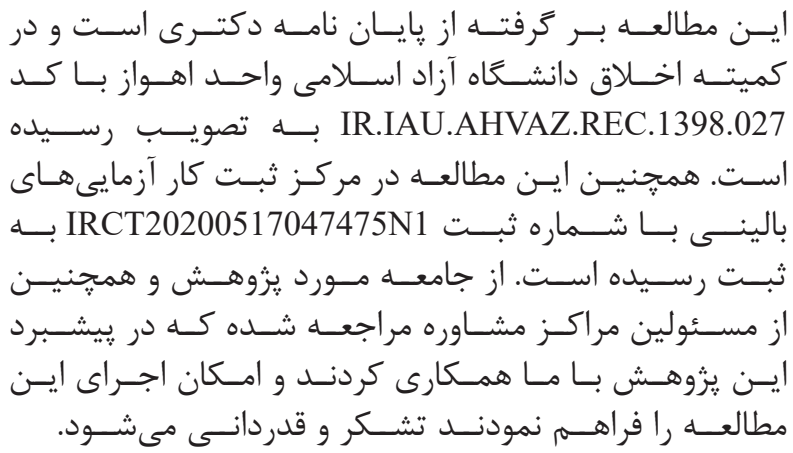

1. Association AP. Diagnostic and Statistical Manual of Mental Disorders DSM-5. Tehran: Arjmand; 2013.

2. Kaplan HI, Sadock BJ. Synopsis of psychiatry: Behavioral sciences clinical psychiatry: Williams \& Wilkins Co; 1988.

3. Bassak Nejad S. The Relationships between Selected Psychological Antecedents and Body Image Concern among Women Seeking Plastic surgery. International Journal of Psychology (IPA). 2007; 1(2).

4. Basaknejad S MHM, Hassani M, Nargesi F. The effectiveness of group narrative therapy on bodybuilding anxiety in female students. Health Psychology. 2012; 2(1): 5-12.

5. Association AP. Diagnostic and statistical manual of mental disorders (DSM-5®): American Psychiatric Pub; 2013.

6. Habibollahi a, Soltanizadeh M. The effectiveness of acceptance and commitment therapy (ACT) on obsessions-compulsions in girl adolescents with body dysmorphic disorder. Shenakht Journal of Psychology and Psychiatry. 2016; 2(4): 1-10.

7. Saffar Pour A. The Book of Mental Exercise and Creativity through Table Games: For Interested Students, Especially in Elementary first and second grade. Tehran: Cultural Institute of Borhan School; 2016. 156 p.

8. Valente-Silva P, Ruas JL. Tryptophan-kynurenine metabolites in exercise and mental health. California: Springer; 2017. p. 83-91.

9. Eskandarnejad m, Fathzadeh 1. The Effect of Aerobic Exercises on Body Image Concern, Identity Crisis and BMI Modification, in Girls with Body Image Concern. Journal of Health Promotion Management. 2017; 6(2): 34-42.

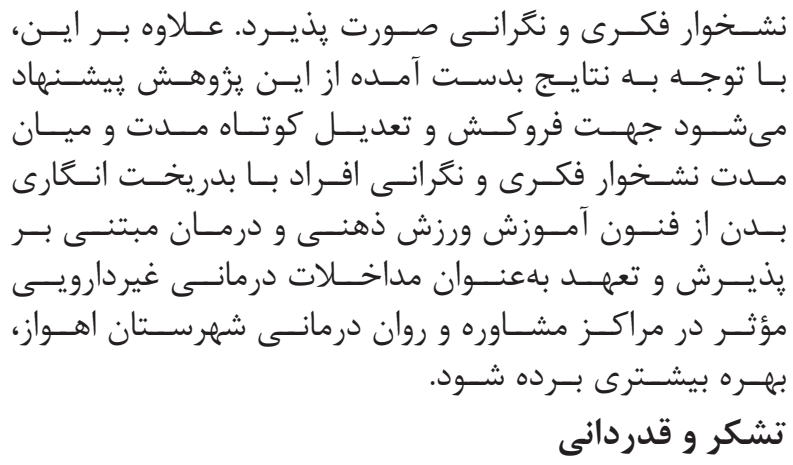

منابع

10. Moshref-Razavi S, Sohrabi M, Sotoodeh MS. Effect of Neurofeedback Interactions and Mental Imagery on the Elderly's Balance. Salmand: Iranian Journal of Ageing. 2017; 12(3): 288-99.

11. Jonasson LS, Nyberg L, Kramer AF, Lundquist A, Riklund K, Boraxbekk C-J.Aerobic exercise intervention, cognitive performance, and brain structure: results from the physical influences on brain in aging (PHIBRA) study. Frontiers in aging neuroscience. 2017; 8: 336.

12. Phillips KA. The broken mirror: Understanding and treating body dysmorphic disorder: Oxford University Press, USA; 2005.

13. Zettle RD. Acceptance and commitment therapy (ACT) vs. systematic desensitization in treatment of mathematics anxiety. The psychological record. 2003; 53(2): 197-215.

14. Harris R. Embracing your demons: An overview of acceptance and commitment therapy. Psychotherapy in Australia. 2006; 12(4): 70 .

15. Hodge K. Sport motivation: Training your mind for peak performance: Raupo; 2010.

16. Millman D. Body mind mastery: Training for sport and life: New World Library; 2010.

17. Rasooli Ali Abadi B, Kalantari M. The Effectiveness of Acceptance and Commitment therapy on depression, self-esteem and body image concerns, after the first birth, women in Kashan city. Avicenna Journal of Nursing and Midwifery Care. 2018; 26(2): 103-12.

18. Gholamhoseini B, Koolaee AK, Taghvaee D. The Effectiveness of acceptance and commitment group 


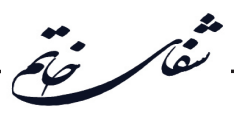

therapy on depression and body image in women with obesity. Community Health (Salāmat-i ijtimāī). 2015; 2(2): 72-9.

19. Twohig MP, Hayes SC, Masuda A. Increasing willingness to experience obsessions: Acceptance and commitment therapy as a treatment for obsessivecompulsive disorder. Behavior therapy. 2006; 37(1): 3-13.

20. Saatchi M, Askarian M, L P. Psychological tests 2. Tehran: Cultural Institute of Borhan School; 2019. 356 p.
21. Bond FW, Hays D. Handbook of brief cognitive behaviour therapy: John Wiley \& Sons; 2005.

22. Veale D. Advances in a cognitive behavioural model of body dysmorphic disorder. Body image. 2004; 1(1): 113-25.

23. Rahnama M, Sajadian A, A R. The Effectiveness of Acceptance and Commitment-Based Therapy on Psychological Distress and Therapeutic Adherence in Cardiac Coronary Patients. Psychiatric Nursing. 2017; 5(4): 34-43. 